\title{
Novel coronavirus, old partisanship: COVID-19 attitudes and behaviors in the United States and \\ Canada
}

\author{
Mark Pickup, Dominik Stecuła ${ }^{\dagger}$ Clifton van der Linden ${ }^{\ddagger}$
}

April 29, 2020

\begin{abstract}
We utilize nationally representative surveys from the United States and Canada to examine the partisan divide in COVID-19 attitudes and behaviours in both countries. The first cases of COVID-19 in both the US and Canada occurred around the same time, but government responses were starkly different. We explore politically salient assessments of governmental performance in both countries, as well as general concern regarding COVID-19 and declarations of changes to daily routines undertaken in response to the pandemic. We find strong partisan differences in evaluations of the government's response to COVID-19 and confidence in its ability to handle the crisis. We also find partisan differences in concern and behavioural responses to the pandemic in both countries. However, the behavioural differences are small, suggesting that while overtly political assessments are strongly partisan this polarization is dampened down when it comes to actual behavioural responses to the pandemic.
\end{abstract}

Keywords: COVID-19; partisanship; concern; confidence; reaction; behaviours

\footnotetext{
${ }^{*}$ Department of Political Science, Simon Fraser University

${ }^{\dagger}$ Centre For Public Opinion and Political Representation, Simon Fraser University; Annenberg Public Policy Center, University of Pennsylvania

${ }_{\ddagger}^{\ddagger}$ Department of Political Science, McMaster University
} 


\section{Introduction}

The novel coronavirus reached the US and Canada almost at the same time, with the first reported American case coming on January 20, 2020 and the first reported Canadian case coming on January 15, 2020 (Holshue et al., 2020; Public Health Agency of Canada, 2020). Yet, the response to this crisis has been quite different in the two countries.

In the United States, President Donald Trump, prominent Republicans and conservative media initially dismissed the dangers of COVID-19 (Stecula, 2020). The pandemic became politicized from the early days, and even though Trump and Republicans have walked back many of their initial claims, there continue to be media reports of partisan differences in public opinion shaped by that early response. At the same time, the response in Canada can be characterized by across-the-board partisan consensus among political elites (Merkley et al., 2020).

Despite these vastly different initial responses by political elites in the US and Canada, we know relatively little about how the publics in both countries compare. In this paper, we examine nationally representative survey data from the US and Canada, fielded in late March and early April, to examine American and Canadian attitudes in relation to topics including concern about COVID-19, evaluations of the federal government's response to the COVID-19 crisis, confidence in the federal government's ability to handle the pandemic, as well as self-declared changes in behaviors recommended by public health experts to combat COVID-19 (such as avoiding crowds and social distancing). We examine these attitudes and behaviors through the prism of partisanship, and whether partisan divisions pose risks to public health in the US and Canada by reducing responses to COVID-19 needed to fight the pandemic. 


\section{Partisanship and polarization of COVID-19 opinion}

Public opinion is shaped, to a large extent, by political elites (Zaller, 1992; Lenz, 2012). At a time of high political polarization, especially in the United States, partisan identities are very salient (Mason, 2018), and, as a result, when trusted political leaders engage on a prominent issue, the public tends to follow . This dynamic is not reserved to purely "political" phenomena, but also scientific issues, such as climate change (Merkley and Stecula, 2020).

The most salient issue at the time of writing is the novel coronavirus global pandemic. Based on polling conducted by the Pew Research Center in the United States, an unprecedented $89 \%$ of Americans have been following the COVID-19 news closely in March (Mitchell and Oliphant, 2020). Public opinion polls in Canada show a similar trend, with threequarters of Canadians closely following news or information about the outbreak (Abacus Data, 2020). With the vast majority of Americans and Canadians paying close attention to COVID-19 news, the messages of political elites are of special importance. Given differences in the degree to which political elites have politicized the issue in the US and Canada, we expect to find higher opinion polarization in the United States. This is important to the extent that it might affect behaviours needed to fight the pandemic.

\section{Data and Methods}

The data employed in this study are sourced from two surveys. The American survey was fielded through Lucid on March 31, $2020(\mathrm{n}=1,009)$. Previous research has found that Lucid is a high quality source of public opinion data (Coppock and McClellan, 2019) and through basic demographic quotas tends to produce samples broadly representative of the US population. We further generate weighting variable using the iterative proportional fitting algorithm based on: whether the respondent is Hispanic or not, white or not, and educational attainment. We use benchmark data from the US Census's Current Population Survey (CPS) from February 2018. The Canadian data comes from Vox Pop Labs COVID- 
19 Monitor initiative, employing data from a rolling sample, collected between 20 March and 7 April $2020(\mathrm{n}=9,889)$. The sample was drawn from an online panel of approximately 650,000 individuals residing in Canada. Weights benchmarked on the 2016 Canadian Census are base on age group, sex, highest level of educational attainment, vote recall in the 2019 Canadian federal election, and region.

Our dependent variables are COVID-19 attitudes and behaviours. Respondents were asked: how concerned they are about the coronavirus pandemic (COVID-19 Concern) ${ }^{1}$; whether they believed that the actions being taken by the federal government in response to the coronavirus were an overreaction, an underreaction, or appropriate (Government Reaction); how confident they are in the federal government's ability to safeguard the health and well-being of the American/Canadian people during the coronavirus pandemic (Government Confidence); and what changes they have made to their normal routine in response to the pandemic (COVID-19 Behaviours) ${ }^{2}$.

Our independent variable is partisanship. In the American sample, this is based on a question asking if the respondent identified as a Republican or Democrat (see Supplementary materials). In the Canadian sample this is based on reported vote in the 2019 federal election.

COVID-19 Concern, Government Reaction, and Government Confidence have categorical response options. We tested for partisan differences using multinomial logit, controlling for demographic variables, and then calculating the average probability of being in each response category holding demographic variables at their observed values for each respondent. ${ }^{3}$ We then tested the statistical significance of differences in probabilities across partisanship. For COVID-19 Behaviours, we calculated the proportion of all possible behaviours each respondent indicated they had engaged in and used a linear regression controlling for de-

\footnotetext{
${ }^{1}$ Canadian respondents were asked how concerned they were about a range of COVID-19 items (see Supplementary Materials), while Americans were simply asked if they were concerned about the pandemic generally. For the Canadian respondents, we use the maximum concern expressed among the first 3 items. Each is about them or others contracting COVID-19.

${ }^{2}$ Respondents were provided a list of 22 items and could select all that applied (see Supplementary Materials).

${ }^{3}$ As a robustness test, we re-ran analysis using ordered probit models. The results are largely unchanged (see Supplementary Materials).
} 
mographic variables. The demographic variables for Canadian respondents are age, gender, income, language, education and region. The demographic variables for US respondents are the same except that ethnicity was substituted for language. ${ }^{4}$

\section{Results}

The results for the US are presented in Figure 1a and the results for Canada are presented in Figures 1b through 1f. Starting with COVID-19 Concern, we can see that Democrats are more likely to say that they are very concerned (57\%) compared to Republicans (43\%). The difference is statistically significant at the 0.05 level. ${ }^{5}$ As a consequence, Democrats are less likely to say that they are only a little concerned or not at all concerned compared to Republicans. For the Canadian case we compare Liberal voters (the governing party) to voters for each of the other parties. We do not see much of a difference between Liberal and Green or NDP supporters. However, Conservatives are somewhat less likely to say they are very concerned (39\%) compared to Liberals (46\%) and Bloc supporters are even less likely to be very concerned $(33 \%)$ and more likely to be a little concerned. These differences are statistically significant. Peoples Party (PPC) supporters are the most different from Liberals, only $29 \%$ of whom indicated they were very concerned. This 17 -percentage point difference is similar to that between Republicans and Democrats.

With respect to assessments of the Government Reaction, Democrats are significantly more likely than Republicans to say it was a slight or significant underreaction (47\% versus 15\%). On this overtly political assessment, there are also statistically significant differences between Liberals and supporters of all other parties in Canada. Of Liberals, $67 \%$ said the response was appropriate. Only $18 \%$ of PPC supporters, $37 \%$ of Bloc supporters, $42 \%$ of Conservatives, $52 \%$ of NDP supporters, and $53 \%$ of Green supporters said the same. Bloc, Green and NDP supporters were more likely to say it was an underreaction. Interestingly,

\footnotetext{
${ }^{4}$ We did not include ideology because to the extent that partisan identity/support determines ideology, including ideology in our models would have resulted in an observational data form of posttreatment bias.

${ }^{5}$ All tests of statistical significant are 0.05 two-tailed tests.
} 
while both Conservative and PPC supporters were more likely to declare the government response an underreaction, they were also more likely to say it was an overreaction. Conservative and PPC supporters are far from united in their assessment of the federal government's reaction to COVID-19 except that they largely agree it was not appropriate.

Turning to Government Confidence, it is far from surprising that Democrats were less likely than Republicans to say that they were very or extremely confident in the federal government's ability to safeguard the health and well-being of the American people during the coronavirus pandemic (33\% versus $69 \%$ ). In Canada, $49 \%$ of Liberals said that they were very or extremely confident in the federal government. Again, not surprisingly, confidence in the federal government is lower amongst supporters of the other parties: Green, 33\%; NDP, 31\%; Bloc, 18\%; Conservatives, 15\%; and PPC, 14\%. Each of these differences are statistically significant.

Next we look at partisan differences in the self-reported behavioural responses to COVID19. On average, Democrats have made $46 \%$ of the behavioural changes that were listed in the survey question in response to the COVID-19 pandemic. In contrast, Republicans have on average made $43 \%$ of these changes. This is not a large difference between supporters of the two parties, but it is statistically significant. Liberals in Canada have made $63 \%$ of the behavioural changes, on average. This is substantially greater than Republicans or Democrats in the US. The behaviours of Green and NDP supporters in Canada are indistinguishable from Liberals. Conservatives, PPC and Bloc supporters are different from Liberals in terms of their reported behaviours, with each having made fewer changes to their daily routines. Only $60 \%$ of Bloc supporters, $59 \%$ of Conservatives supporters, and $51 \%$ of PPC supporters report having made any such changes. Each of these differences are statistically significant. The greatest behavioural differences are between Liberal and PPC supporters, although even PPC supporters have engaged in great levels of compliance with public health guidance than Democrats in the US. The next greatest differences are between Democrats and Republicans, and between Liberals and Bloc or Conservative supporters. 
Figure 1

(a) Democrats/Republicans

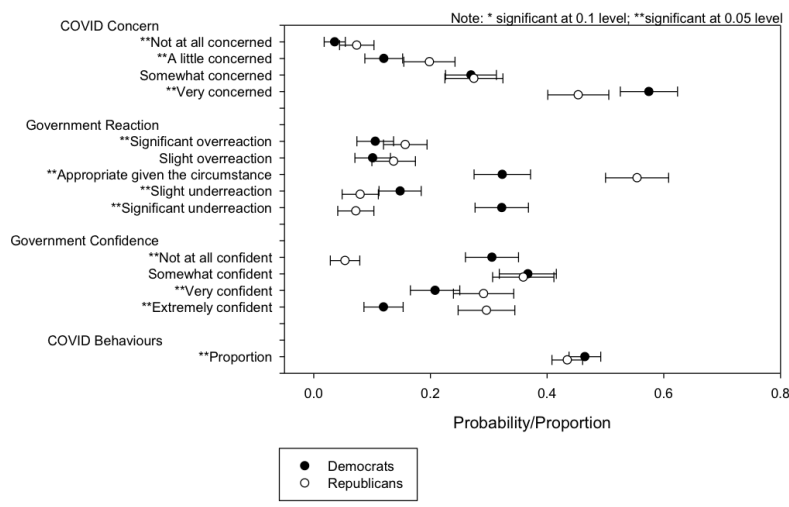

(c) Liberals/Bloc

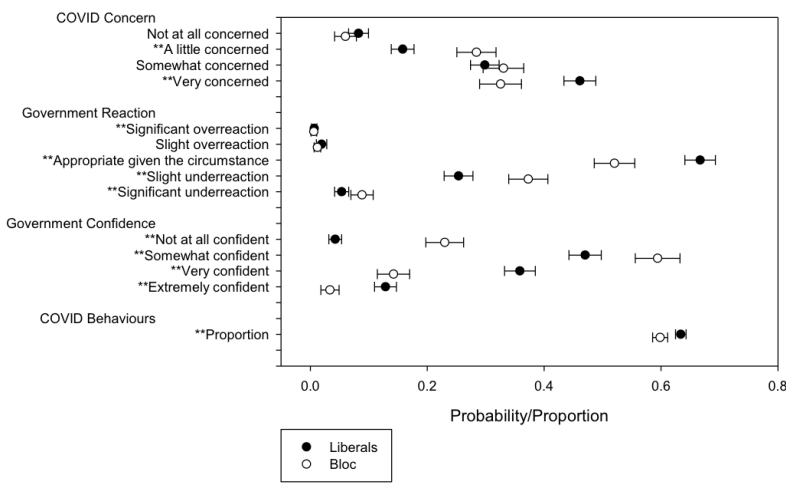

(e) Liberals/Green

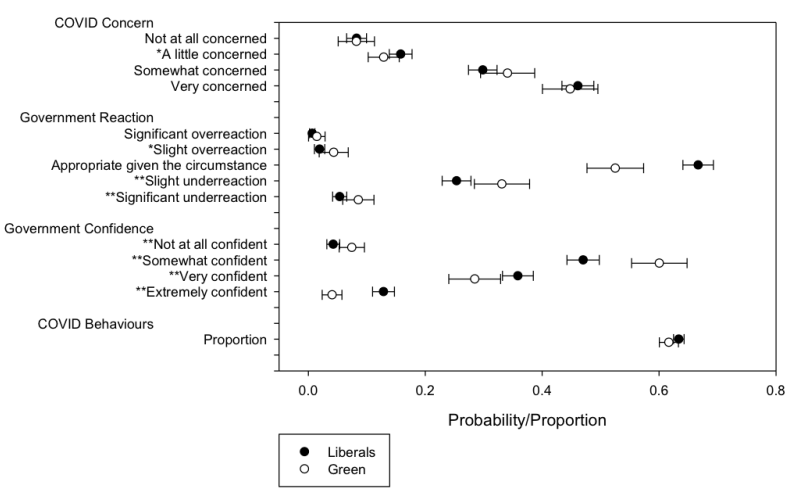

(b) Liberals/Conservatives

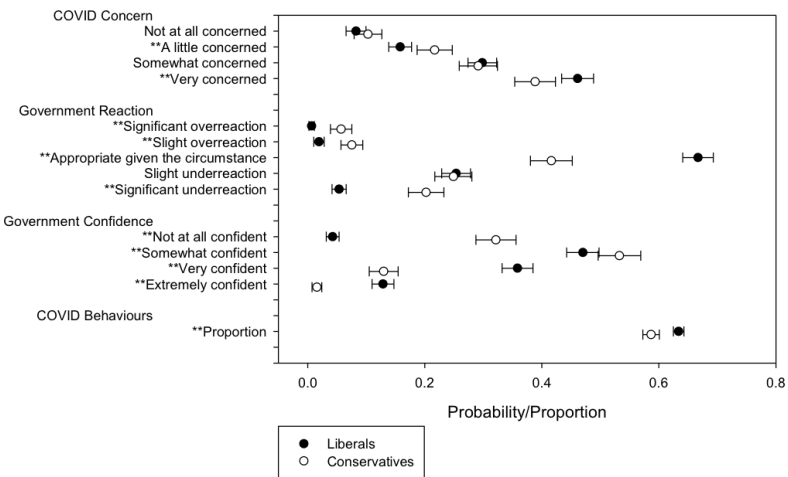

(d) Liberals/People's Party

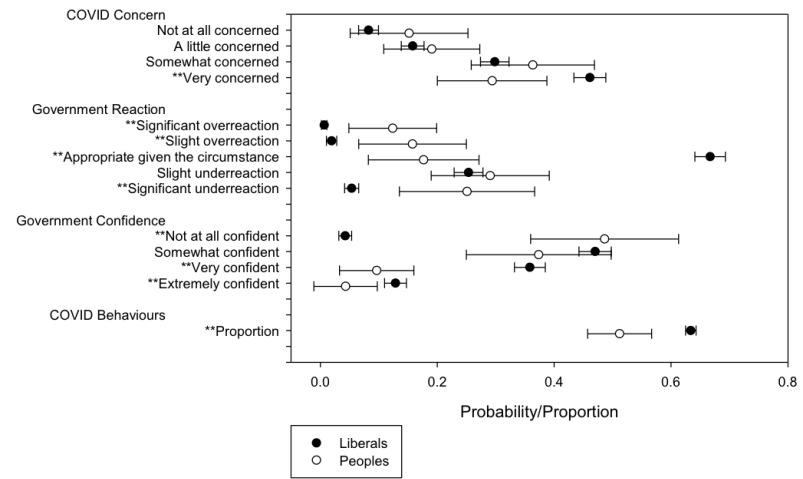

(f) Liberals/NDP

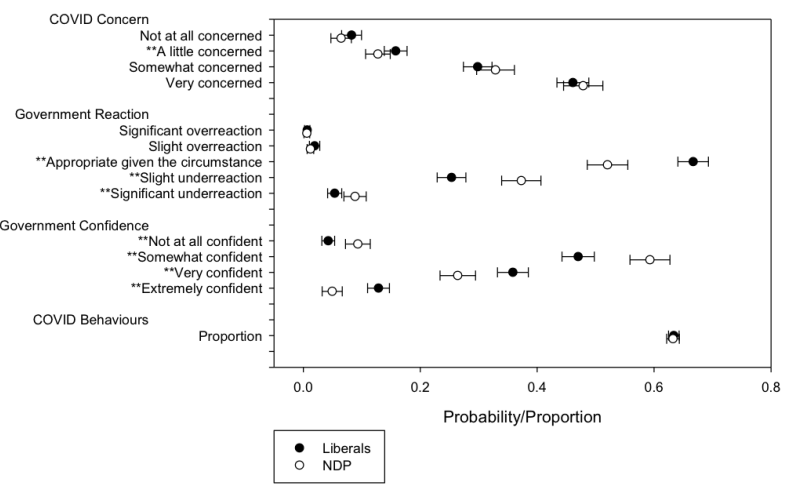

With the exception of PPC supporters, of which there are few, these behavioural differences are small. 


\section{Conclusion}

Unsurprisingly, partisanship drives political assessments of the federal government's response to COVID-19 in both Canada and the US. The gap between Democrats and Republicans in their confidence in the government to handle the crisis is the same as the gap between Liberals and supporters of the Conservatives and PPC. It is more surprising that there are partisan differences in concern about COVID-19 - not just in the US but also in Canada, where there has been remarkable cross-partisan consensus about COVID-19 among partisan elites.

Encouragingly, we find that these differences are much smaller when it comes to behavioural responses to the pandemic. The gap between Republicans and Democrats, and between Liberals and supporters of most other parties in Canada is very small in magnitude. The largest difference is between the small number of Peoples' Party supporters and Liberals. This suggests that while overtly political assessments are strongly partisan this polarization is dampened down when it comes to actual behavioural responses to the pandemic. Partisan divisions have the potential to pose public health risks by reducing healthy behavioural

responses to COVID-19 but that potential is not being realized in a substantively significant way in either the US or Canada. 


\section{References}

Abacus Data (2020). Covid-19 and canadians' state of mind: Worried, lonely, and expecting disruption for at least 2 to 3 months. https://abacusdata.ca/coronavirus-covid19abacus-data-mood-polling/.

Coppock, A. and McClellan, O. A. (2019). Validating the demographic, political, psychological, and experimental results obtained from a new source of online survey respondents. Research Politics, 6(1):1-14.

Holshue, M. L., DeBolt, C., Lindquist, S., Lofy, K. H., Wiesman, J., Bruce, H., Spitters, C., Ericson, K., Wilkerson, S., Tural, A., Diaz, G., Cohn, A., Fox, L., Patel, A., Gerber, S. I., Kim, L., Tong, S., Lu, X., Lindstrom, S., and Pillai, S. K. (2020). First case of 2019 novel coronavirus in the united states. New England Journal of Medicine, 382(10):929-936.

Lenz, G. (2012). Follow the Leader?: How Voters Respond to Politicians' Policies and Performance. University of Chicago Press.

Mason, L. (2018). Uncivil Agreement: How Politics Became Our Identity. University of Chicago Press.

Merkley, E., Bridgman, A., Loewen, P. J., Owen, T., Ruths, D., and Zhilin, O. (2020). A rare moment of cross-partisan consensus: Elite and public response to the covid-19 pandemic in canada. Open Science Framework, [Preprint]. https://doi.org/10.31219/osf.io/ xas4u.

Merkley, E. and Stecula, D. (2020). Party cues in the news: Democratic elites, republican backlash and the dynamics of climate skepticism. British Journal of Political Science, [Forthcoming]. https://doi.org/10.31219/osf.io/azrxm.

Mitchell, A. and Oliphant, J. B. (2020). Americans immersed in coronavirus news; most think media are doing fairly well covering it. Technical report, Pew Research Center's Journalism Project. https://www . journalism.org/2020/03/18/americans-immersedin-covid-19-news-most-think-media-are-doing-fairly-well-covering-it/.

Public Health Agency of Canada (2020). Epidemiological summary of COVID-19 
cases in Canada. https://health-infobase.canada.ca/covid-19/epidemiologicalsummary-covid-19-cases.html.

Stecula, D. (2020). What do we know about misinformation during the coronavirus outbreak? https://www.mischiefsoffaction.com/post/what-do-we-know-aboutmisinformation-during-the-coronavirus-outbreak.

Zaller, J. (1992). The Nature and Origins of Mass Opinion. Cambridge University Press. 


\section{Supplementary Materials}

\subsection{Government Confidence}

\section{United States}

How concerned are you about the coronavirus pandemic?

- Not at all concerned

- A little concerned

- Somewhat concerned

- Very concerned

\section{Canada}

How concerned would you say you are right now about each of the following?

- Personally contracting COVID-19

- A friend or family member contracting COVID-19

- Someone in your local community contracting COVID-19

- Your ability to pay your bills

- Your job security

- The availability of food and supplies in your area

- The ability of the public health care system to provide adequate care in the event of illness or injury

- The Canadian economy

- The global economy

- The government response to the COVID-19 pandemic Other (Please specify):

- Not at all concerned

- A little concerned

- Somewhat concerned

- Very concerned 


\subsection{COVID-19 Behaviours}

What changes, if any, have you made to your normal routine in response to the COVID-19 pandemic? (Please select all that apply)

- Washing hands more often with soap and water

- Cleaning and disinfecting frequently touched surfaces and objects more often

- Using alcohol-based hand sanitizers more often

- Not going into work or working from home more than usual

- Avoiding all non-essential in-person contact outside your household

- Staying in a separate room from others in your home

- Using a separate bathroom from others in your home

- Avoiding gatherings of more than 10 people

- Avoiding gatherings of more than 50 people

- Avoiding common greetings, such as handshakes

- Avoiding crowded places

- Keeping a distance of at least 2 arms lengths (approximately $6 \mathrm{ft}$ ) from others, as much as possible

- Coughing or sneezing into a tissue or the bend of your arm instead of your hand

- Avoiding touching your eyes, nose, or mouth with unwashed hands

- Avoiding travel outside America

- Avoiding travel within America

- Shifting more of your shopping from physical stores to online

- Avoiding people who are more likely to have come in contact with the coronavirus such as those who have recently traveled internationally

- Avoiding public transit

- Wearing a disposable mask

- Wearing disposable gloves

- Other 


\subsection{Government Response}

Do you believe that the present action being taken by the federal government in response to the coronavirus (COVID-19) is an overreaction, an underreaction, or appropriate given the circumstances?

- Significant overreaction

- Slight overreaction

- Appropriate given the circumstances

- Slight underreaction

- Significant underreaction

- Don't know

\subsection{Government Confidence}

How confident are you in the federal government's ability to safeguard the health and wellbeing of the American people during the coronavirus (COVID-19) pandemic?

- Not at all confident

- Somewhat confident

- Very confident

- Extremely confident

- Don’t know

\subsection{Partisan Identity}

Generally speaking, do you usually think of yourself as a Republican, a Democrat, an Independent, or something else?

\section{United States}

- Republican

- Democrat

- Independent

- None of these

\section{Canada}

Which party did you vote for in the 2019 Canadian federal election? 
- Bloc Québécois

- Conservative Party of Canada

- Green Party of Canada

- Liberal Party of Canada

- New Democratic Party (NDP)

- People's Party of Canada

- Other (Please specify) 


\subsection{Ordered Probit Results}

Figure 2

(a) Democrats/Republicans

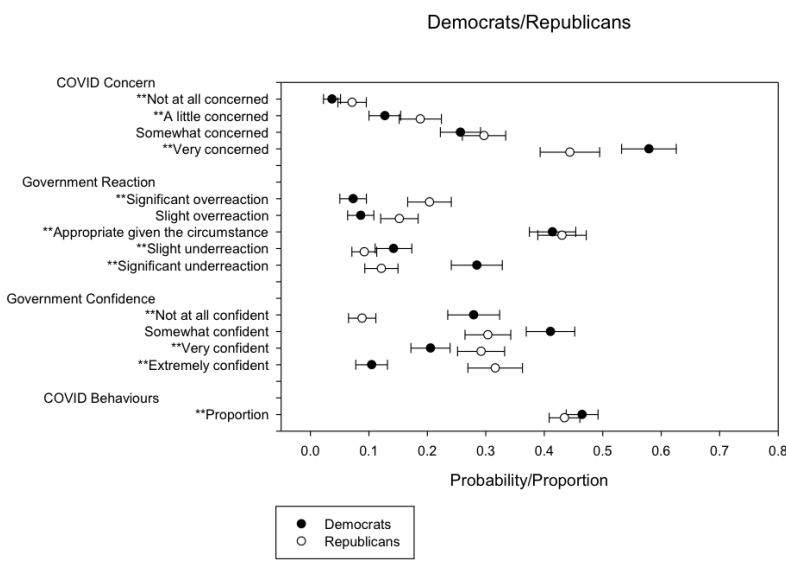

(c) Liberals/Bloc

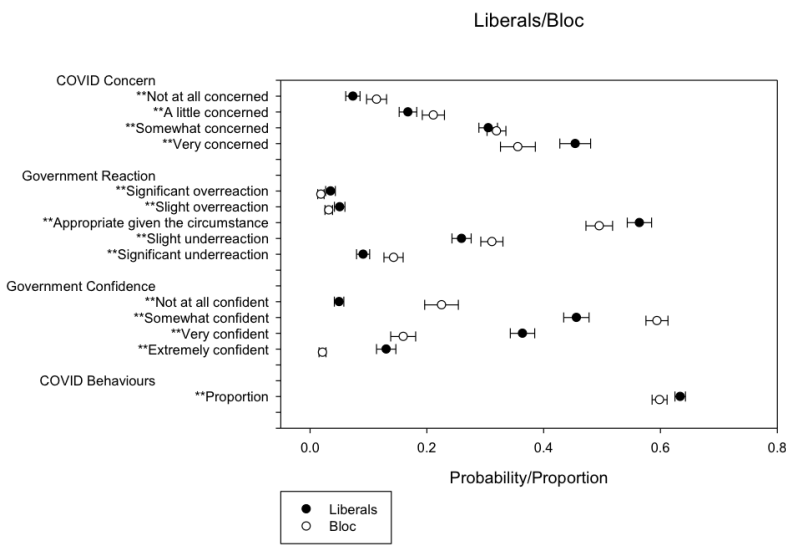

(e) Liberals/Green

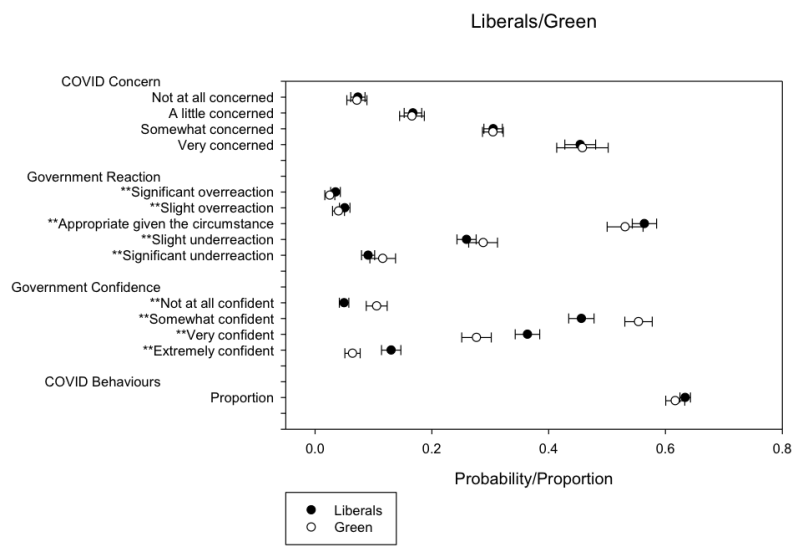

(b) Liberals/Conservatives

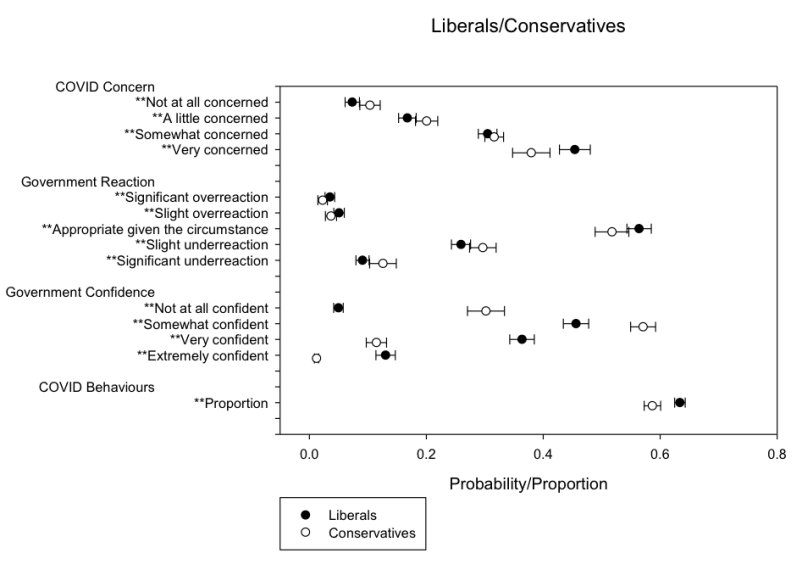

(d) Liberals/People's Party

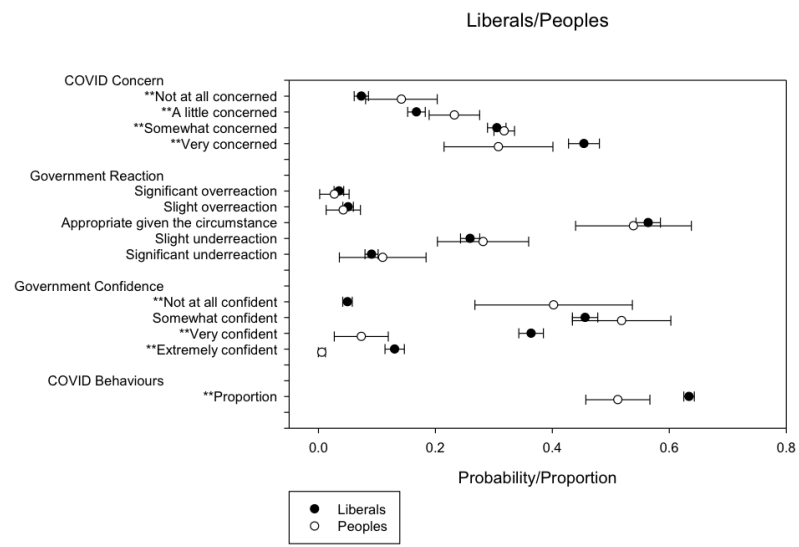

(f) Liberals/NDP

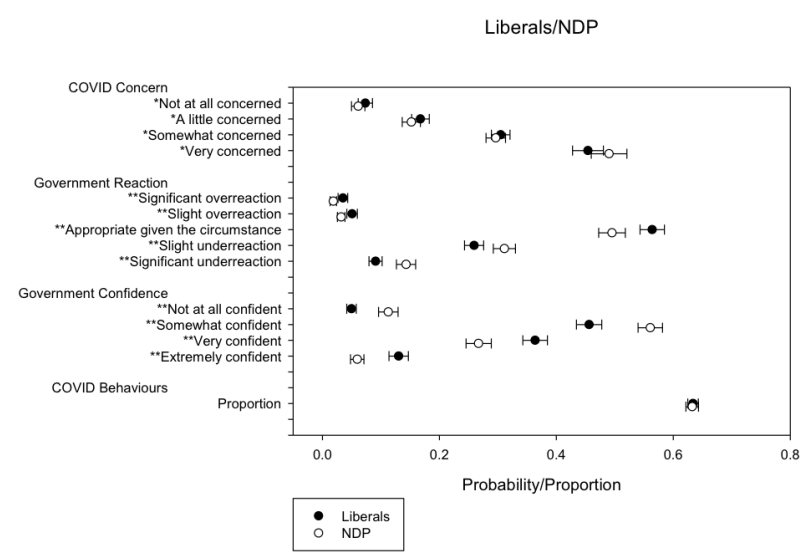

